\title{
Mechanism of the Reaction of Plasma Albumin with Formaldehyde in Ethanol - Water Mixtures and Water Solution Using Bronsted-Type Plot Model
}

\author{
Ugye, T. J' ${ }^{1}$, Uzairu A ${ }^{2}$, Idris, S. $\mathrm{O}^{2}$, Kwanashie H. $\mathrm{O}^{3}$. \\ ${ }^{I}$ Department of Chemical Sciences, Federal University, P.M.B 1020 Wukari \\ ${ }^{2}$ Department of Chemistry, Ahmadu Bello University, Zaria. \\ ${ }^{3}$ Department of Pharmacology and Therapeutics, Ahmadu Bello University, Zaria.
}

\begin{abstract}
The Spectrophotometric determination of the acid dissociation/ionisation constant (pKa) of plasma albumin-formaldehyde adduct in both water solution and Ethanol solutions was carried out in this study. The $p K a$ values obtained in both media were used to establish the Bronsted-linear type constants from plots of $p K a$ against logarithm of second order rate constants obtained at varying $\mathrm{pHs}$ in the study. The result of the $\mathrm{pKa}$ values obtained in both water solution and ethanol-water mixtures were found to be in the range of $5.0-8.0$. This pointed to the fact that only lysine residue with $\mathrm{pKa}$ value 8.3 that might have possibly reacted with formaldehyde in this reaction of all the known amino acid residues in plasma albumin. The corresponding Brønsted-type plots proportionality constants $(\beta)$ for the reaction in water and ethanol-water mixtures were found to be $\beta=0.059$ and 0.0057 respectively. The reaction mechanisms that have low values for proportionality constants $\alpha$ or $\beta$ are considered to have a transition state closely resembling the reactant with little proton transfer (Cox et al, 1988). Thus, one would suggest that the cross-linking of formaldehyde with plasma albumin in water and ethanol-water mixtures proceeds through little proton transfer
\end{abstract}

Keywords: Spectrophotometric determination, $\mathrm{pKa}$, Bronsted-type plot, ethanol-water mixtures, water solution

\section{Introduction}

The Bronsted-type proportionality constant is a slope ratio obtained from a plot logarithm of a second order rate constant $\left(\log \mathrm{k}_{2}\right)$ against the pKa values of a species and it is usually represented as $\alpha$ or $\beta$ based on its acidic or basic nature. According to [1] the linear free energy relationships have proven to be valuable tools in studies of reaction mechanisms, in particular in determining the changes in transition state (TS) structure due to partial bond formation or secession and the magnitude of $\beta_{\text {nuc }}$ values has been used as a measure of reaction mechanism. If proton transfer is complete in the transition state then the change in the free energy of the transition state should be the same as the change in free energy for the reference reaction; slope $=1 .[1,2]$. The workers also noted that the Brønsted equation as a free - energy relationship implies that the Gibbs free energy for proton dissociation is proportional to the activation energy for the catalytic step. When the relationship is not linear, the chosen group of catalysts do not operate through the same reaction mechanism. The reaction mechanisms that have low values for proportionality constants $\alpha$ or $\beta$ are considered to have a transition state closely resembling the reactant with little proton transfer while those with a high value indicate that the proton transfer in the transition state is almost complete [1].

The Bronsted slope is also reported to be a rough measure of the extent of proton transfer at the transition state: how much does the transition state respond to a change in catalyst relative to the change in the reference reaction. When the Bronsted plot proportionality constant $\alpha$ or $\beta$ is 1.0 , it means, proton is fully transferred and when $\alpha$ or $\beta=0.0$ it entails that proton is not transferred at all. When $\alpha$ or $\beta$ are in between, it means the proton is in "flight" at the transition state. The studies of $[2,3]$ reported that Linear Brønsted-type plot with $\beta_{\text {nuc }}=0.88$ in the $\mathrm{pK}$ range $5.95-11.02$ were concluded to proceed through a stepwise mechanism in which breakdown of the intermediate is the rate determining step. On the other hand, reactions which proceed through a concerted mechanism have often been reported to result in a $\beta_{\text {nuc }}$ value of $0.5 \pm 0.1$.Accordingly, one can suggest from results of this current study that the reaction between plasma albumin and formaldehyde have low values for linear Bronsted constants $\beta=0.057$ and could be considered to have a transition state closely resembling the reactant with little proton transfer.

The $\mathrm{pKa}$ of a chemical species is its acidity or basicity dissociation/ionisation constant ( $\mathrm{pKa}$ or $\mathrm{pKb}$ ). A number of factors are reported to influence the $\mathrm{pKa}$ of an ionizable amino acid side chains in a protein, these include the electrostatic field of the protein (especially the local charge distribution around the particular side chain), the solvation of the group and the hydrogen bonds, if any, that the group may be involved in. An examination of the $\mathrm{pKa}$ values commonly found in protein side chains have reported to be in a range from 
approximately 3.75 to $>12$ [4]. Proteins are known to react with formaldehyde based on amine chemistry to form intermediate hydroxymethyl groups that drives a basicity loss with $\mathrm{pK}$ drops of about 4-5 units [5]. The associated changes in the UV-visible spectrum of a compound upon ionisation can be used in order to establish its acidity or basicity constant ( $\mathrm{p} K$ ). Accordig to [6] it is usually necessary to compare the spectrum of a free substrate (plasma albumin) to those of a closely related derivative lacking the properties of the original group. In this present case we compared the absorption of $51 \times 10^{-4} \mathrm{~mol} \mathrm{dm}^{-3}$ plasma albumin to that of its adduct with $0.27 \times 10^{-2} \mathrm{~mol} \mathrm{dm}^{-3}$ formaldehyde absorption at $\mathrm{pH}$ range of 5.3- 8.7.

\section{Materials and method}

The Spectrophotometric determinations of the $\mathrm{pKa}$ of plasma albumin-formaldehyde adduct in both water solution and Ethanol solutions were done using a procedure similar to that of [7] where differences in the absorption of the $0.51 \times 10^{-4} \mathrm{~mol} \mathrm{dm}^{-3}$ plasma albumin and its Plasma albumin-formaldehyde adduct at 235 $\mathrm{nm}$ were measured at varying $\mathrm{pH}$ and the molar absorptivity calculated. A solution of $0.5 \mathrm{moldm}^{-3} \mathrm{NaCl}$ and a self buffering solution of $\mathrm{NaOH}-\mathrm{HCl}$ at a temperature of $\left(37^{\circ} \mathrm{C}\right)$ and varying $\mathrm{pH} 5.3-8.8$ in water and varying ethanol-water mixtures of different permittivities of 78-64.9, were used. The absorbance of both plasma albumin and the formaldehyde - plasma albumin adduct in the two media were measured separately at the selected $\mathrm{pH}$ in a spectrophotometer cuvette and the absorbance values recorded. Triplicate measurements were made at each selected $\mathrm{pH}$ and the mean absorbance value taken. The difference in absorbance was obtained and the molar absorptivity values calculated. The $\mathrm{pKa}$ values were obtained from plots of molar absorptivity $\Delta_{\varepsilon 235}$ versus $\mathrm{pH}$ and $1 / \Delta \varepsilon_{235}$ versus $\left[\mathrm{H}^{+]}\right.$from the relation $1 / \Delta \varepsilon_{235}=[\mathrm{H}+] / \varepsilon_{235} . \mathrm{Ka}+1 / \varepsilon_{235}$ and the Bronsted constants determined from the slopes of the plots of $\operatorname{logk}_{2}$ against the $\mathrm{pKa}$ values obtained (Tong, 2003). The $\mathrm{k}_{2}$ values used were taken from earlier investigations in this study.

\section{Conclusion}

The pKa values obtained in both water solution and ethanol-water mixtures were found to be in the range of $\mathrm{pH} 5.0-8.0$, tending towards alkaline region. The corresponding Brønsted-type plots proportionality constants $(\beta)$ for the reaction in water and ethanol-water mixtures were found to be $\beta=0.059$ and 0.0057 respectively. The reaction mechanisms that have low values for proportionality constants $\alpha$ or $\beta$ are considered to have a transition state closely resembling the reactant with little proton transfer ( Cox et al, 1988). Thus, one would suggest that the cross-linking of formaldehyde with plasma albumin in water and ethanol-water mixtures proceeds through transition state which have low values for linear Bronsted constants $\beta=0.059$ and 0.057 and could be considered to have a transition state closely resembling the reactant with little proton transfer and base catalysed.

\section{Competing interests:}

The Authors wish to declare that there are no conflicts of interest associated with this work.

\section{Authors' contributions:}

Professor Uzairu, A; H.O Kwanashie, H.O, and Idris, S. O conceived and designed the research as well as carefully proof read the the manuscript. Ugye, T. J performed the analysis and prepared the draft manuscript.

\section{Acknowledgements}

This work was not supported by any donor agent, however we wish to appreciate the contributions of Prof. Kehinde Okonjo of the Department of Chemistry, Convenant University, Ota - Nigeria, Dr. S.G Yiase and Mr S.O Adejo as well as the technical staff of ABU Zaria and the Benue State University, Makurdi for their assistance and in facilitating the conduct of the bench Chemistry of this study in their various laboratories.

\footnotetext{
Abbreviations:

$\log \mathrm{k}_{2}$ : Logarithm of second order rate constant

$\mathrm{pK}$ : Acidity or basicity constant

TS : Transition state structure

$\beta=$ Alkaline bronsted plot proportionality constant

$\alpha=$ Acid bronsted plot proportionality constant

$\left[\mathrm{H}^{+}\right]=$Hydrogen ion

$\Delta_{\varepsilon 235}=$ Change in molar absorptivity at wavelength of $255 \mathrm{~nm}$

$1 / \Delta \varepsilon_{235}=$ Reciprocal of change in molar absorptivity at wavelength of $255 \mathrm{~nm}$

$\mathrm{HCHO}$ : Formaldehyde
} 
$\mathrm{PABNH}_{2}$ : Plasma albumin

$\mathrm{PABNHOCH}_{2}$ : Plasma albumin- formaldehyde adduct

Table 1 Experimental data of the effect of $\mathrm{pH}$ on the absorbance of plasma albumin and formaldehydeplasma albumin adduct at varying $\mathrm{pH}$ and constant conditions in Ethanol -water mixtures , Temperature $\mathrm{T}=$ $37.0{ }^{0} \mathrm{C}$, formaldehyde $\left[0.27 \times 10^{-1}\right]$, Plsma albumin $\left.\left[0.51 \times 10^{-4}\right] \mathrm{NaCl}[0.5] \mathrm{moldm}^{-3}\right] \mathrm{pH}=(5.3-8.0), \lambda \mathrm{max}=$

\begin{tabular}{|c|c|c|c|c|c|c|c|c|c|}
\hline \multirow{3}{*}{$\mathrm{pH}$} & \multicolumn{9}{|c|}{$235 \mathrm{~nm}$} \\
\hline & Absorbance & & $\Delta \mathrm{Abs}_{235}$ & $\Delta \varepsilon_{235}$ & $1 / \Delta \varepsilon_{235}$ & {$\left[\mathrm{H}^{+}\right]$} & $\%$ Eth- & $\mathrm{D}$ & $\mathrm{k}_{2}$ \\
\hline & $\mathrm{PABNH}_{2}$ & $\mathrm{PABNHOCH}_{2}$ & & $\mathrm{M}^{-1} \mathrm{~cm}^{-1}$ & & & $\mathrm{H}_{2} \mathrm{O}$ & & \\
\hline 5.3 & 1.445 & 1.480 & 0.035 & 2541.76 & $3.93 \times 10^{-4}$ & $5.01 \times 10^{-6}$ & 1 & 78.0 & 1.89 \\
\hline 6.4 & 1.450 & 1.497 & 0.047 & 3413.22 & $2.93 \times 10^{-4}$ & $3.98 \times 10^{-7}$ & 5 & 75.5 & 2.56 \\
\hline 6.7 & 1.463 & 1.520 & 0.057 & 4139.43 & $2.42 \times 10^{-4}$ & $1.99 \times 10^{-7}$ & 10 & 73.1 & 2.59 \\
\hline 6.9 & 1.471 & 1.543 & 0.072 & 5228.76 & $1.91 \times 10^{-4}$ & $1.26 \times 10^{-7}$ & 15 & 70.4 & 2.59 \\
\hline 7.3 & 1.475 & 1.556 & 0.081 & 5882.35 & $1.70 \times 10^{-4}$ & $5.01 \times 10^{-8}$ & 20 & 67.6 & 2.63 \\
\hline 8.0 & 1.500 & 1.596 & 0.096 & 6971.68 & $1.43 \times 10^{-4}$ & $1.0 \times 10^{-8}$ & 25 & 64.9 & 2.67 \\
\hline
\end{tabular}

K2 values from our current study on effect of $\mathrm{pH}$ on rate constant at $2.7 \times 10^{-1} \mathrm{~mol} / \mathrm{dm}^{3} \mathrm{HCHO}$ of formaldehyde with Plasma albumin reaction at $37^{\circ} \mathrm{C}$ and varying Ethanol-water mixtures

Table 2 Experimental data of the effect of $\mathrm{pH}$ on the absorbance of plasma albumin and formaldehydeplasma albumin adduct at varying $\mathrm{pH}$ and constant conditions in Water solution, Temperature $\mathrm{T}=37.0^{\circ} \mathrm{C}$ formaldehyde $\left[0.27 \times 10^{-1}\right]$, Plsma albumin $\left.\left[0.51 \times 10^{-4}\right] \mathrm{NaCl}[0.5] \mathrm{moldm}^{-3}\right] \mathrm{pH}=(5.3-8.0), \lambda \max =235 \mathrm{~nm}$

\begin{tabular}{|c|c|c|c|c|c|c|c|c|}
\hline \multirow[t]{2}{*}{$\mathrm{pH}$} & \multirow{2}{*}{$\begin{array}{l}\text { Absorbance } \\
\mathrm{PABNH}_{2}\end{array}$} & \multirow{2}{*}{\multicolumn{2}{|c|}{$\mathrm{PABNHOCH}_{2} \quad \Delta \mathrm{Abs}_{235}$}} & \multirow{2}{*}{$\begin{array}{l}\Delta \varepsilon_{235} \\
\mathrm{M}^{-1} \mathrm{~cm}^{-1}\end{array}$} & \multirow[t]{2}{*}{$1 / \Delta \varepsilon_{235}$} & \multirow[t]{2}{*}[\mathrm{H}^{+}]{} & \multirow[t]{2}{*}{$\mathrm{k}_{2}$} & \multirow[t]{2}{*}{$\operatorname{Logk}_{2}$} \\
\hline & & & & & & & & \\
\hline 5.3 & 1.470 & 1.490 & 0.020 & 1452.43 & $6.89 \times 10^{-4}$ & $5.01 \times 10^{-6}$ & 0.69 & -0.16 \\
\hline 6.4 & 1.472 & 1.493 & 0.021 & 1525.05 & $6.56 \times 10^{-4}$ & $3.98 \times 10^{-7}$ & 0.82 & -0.09 \\
\hline 6.7 & 1.475 & 1.497 & 0.022 & 1597.68 & $6.26 \times 10^{-4}$ & $1.99 \times 10^{-7}$ & 0.86 & -0.07 \\
\hline 6.9 & 1.480 & 1.503 & 0.023 & 5670.30 & $1.76 \times 10^{-4}$ & $1.26 \times 10^{-7}$ & 0.86 & -0.07 \\
\hline 7.3 & 1.484 & 1.508 & 0.024 & 5882.35 & $1.70 \times 10^{-4}$ & $5.01 \times 10^{-8}$ & 0.98 & -0.01 \\
\hline 8.0 & 1.488 & 1.514 & 0.026 & 6971.68 & $1.43 \times 10^{-4}$ & $1.0 \times 10^{-8}$ & 1.11 & 0.005 \\
\hline
\end{tabular}

$\mathrm{K} 2$ values from our current study on effect of $\mathrm{pH}$ on rate constant at $2.7 \times 10^{-1} \mathrm{~mol} / \mathrm{dm}^{3} \mathrm{HC} \mathrm{HO}$ of formaldehyde with Plasma albumin reaction at $37^{\circ} \mathrm{C}$ in water solution

Table $3 \mathrm{pKa}$ values of some amino acids and dielectric constant values from ethanol-water mixtures ( D $=78.0-64.9)$ at $37^{\circ} \mathrm{C}, \mathrm{pH}=5.3-8.4$ and ionic strenght of $0.5[\mathrm{NaCl}]$ from literature

\begin{tabular}{|c|c|c|c|c|}
\hline \multicolumn{2}{|c|}{ Eth- $\mathrm{H}_{2} \mathrm{O} \%\left[\right.$ Eth- $\left.\mathrm{H}_{2} \mathrm{O}\right]$} & $\mathrm{pK}$ & $\left.\left[\mathrm{H}_{2} \mathrm{O}\right)\right]$ & D \\
\hline & $\mathrm{M}^{-1} \mathrm{~cm}^{-1}$ & \multicolumn{3}{|l|}{ moldm $^{-3}$} \\
\hline 1 & 0.17 & 8.61 & 55.00 & 78.0 \\
\hline 5 & 0.86 & 8.50 & 52.8 & 75.5 \\
\hline 10 & 1.72 & 8.31 & 50.00 & 73.1 \\
\hline 15 & 2.58 & 8.21 & 47.22 & 70.4 \\
\hline 20 & 3.44 & 8.13 & 44.44 & 67.6 \\
\hline 25 & 4.30 & 8.05 & 41.67 & 64.9 \\
\hline
\end{tabular}

pK values from of the data of Tong ,(200

Table 4 Experimental $\mathrm{pK}$ values of plasma albumin and Plasma albumin-formaldehyde adduct from water solution and second order rate constant values at $37^{\circ} \mathrm{C}, \mathrm{pH}=5.3-8.0$ and ionic strenght of $0.5[\mathrm{NaCl}]$

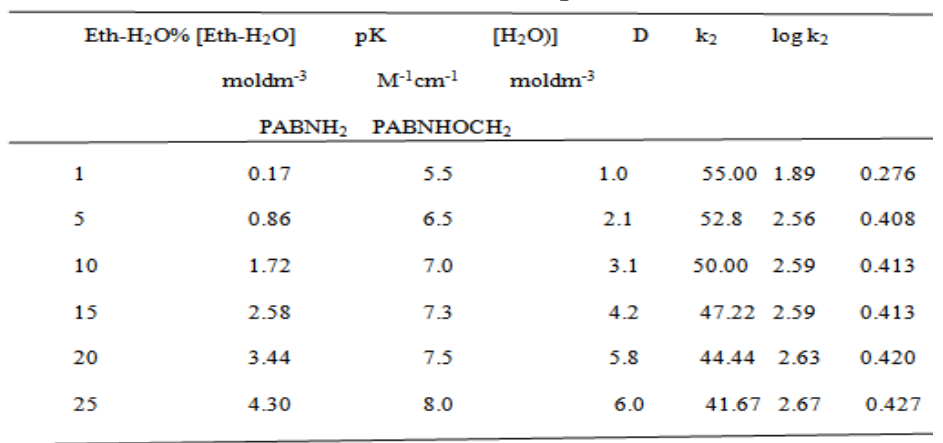




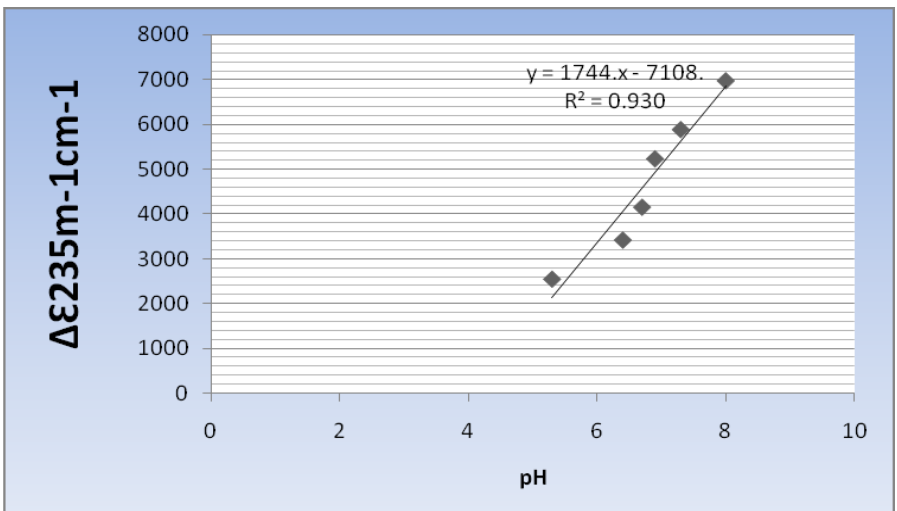

Fig.1 pKa values of plasma albumin a from plot of molar absorptivity vs. $\mathrm{pH}$ for the reaction of plasma albumin with formaldehyde in varying ethanol-water mixtures at $37^{0} \mathrm{C}$ at $\mathrm{pH}, 5.3-8.0$

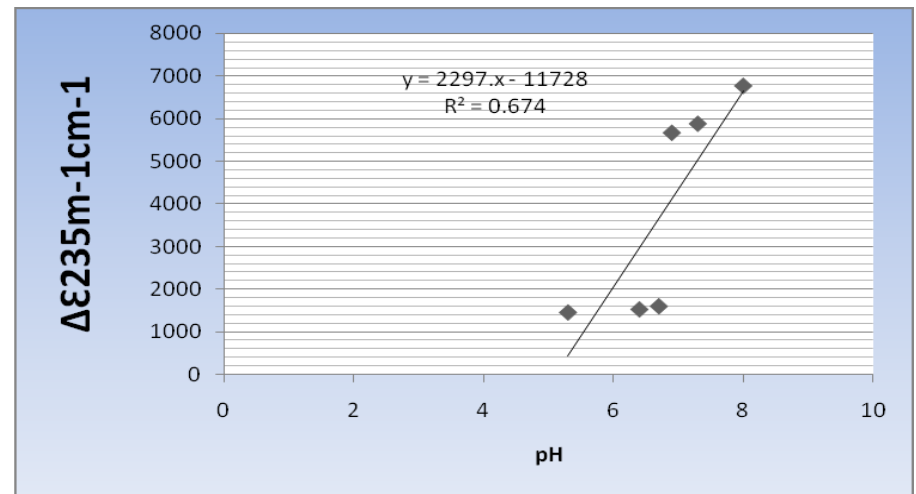

Fig. 2 pKa values of $\mathrm{PABNHOCH}_{2}$ from plot of molar absorptivity vs. $\mathrm{pH}$ for the reaction of plasma albumin with formaldehyde in water solution at $37^{\circ} \mathrm{C}$ at $\mathrm{pH}, 5.3-8.0$

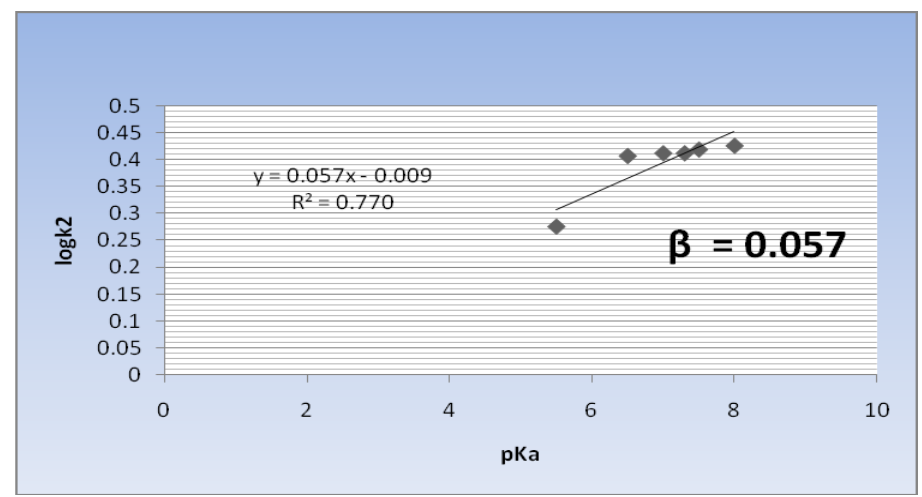

Fig. 3 Bronsted-type plot of log $\mathrm{k} 2$ vs. pK of plasma albumin in the reaction between plasma albumin and formaldehyde in varying ethanol-water mixtures $(1.0-25 \%)$ at $37^{\circ} \mathrm{C}$ at $\mathrm{pH}, 5.3-8.0$

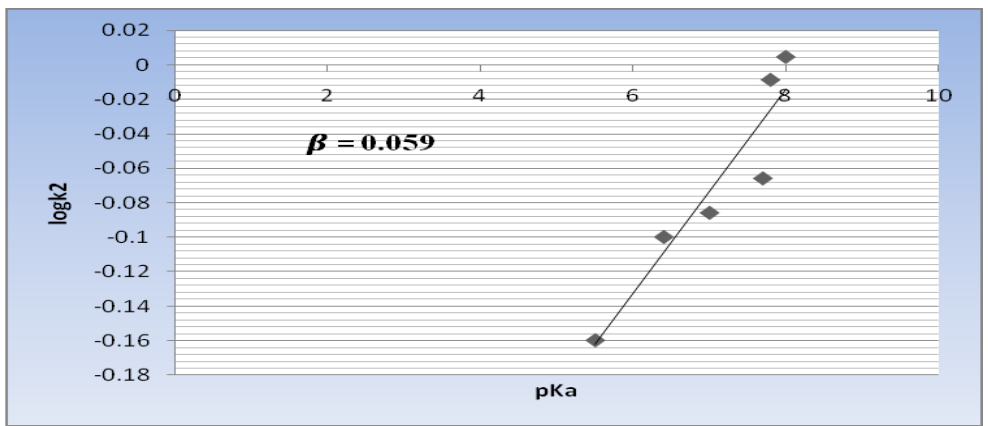

Fig.4 Bronsted-type plot of $\log \mathrm{K} 2$ vs. pK of $\mathrm{PABNHOCH}_{2}$ in the reaction of plasma albumin with formaldehyde in water solution at $37^{\circ} \mathrm{C}$ at $\mathrm{pH}, 5.3-8.0$ 


\section{References}

[1]. Cox, B.G ; Kresge, A.J and Sorensen, P.E. The significance of bronsted plots and deviations from them in the acid- and base catalysed décomposition of some Benzaldehyde ethyl hemiacetals and hydrates. Acta Chemica Scandinavica A42, $1988,202-213$.

[2]. Mihai, C; Kravchuk, A. V; Tsai, M and Bruzik, K.S. Application of Brønsted-Type LFER in the Study of the Phospholipase C Mechanism. J. American Chem. Soc. 125, 2003, 3236-3242

[3]. Shin, Young-Hee; Kim, Eun-Hee; and Um Ik-Hwan( 2008) Reaction Mechanism and Structure of Transition State Determined from Analysis of Brønsted ßnuc for Aminolysis of 4-Nitrophenyl Diphenylphosphinate.. Bull. Korean Chem. Soc, Vol. 29(12), 2008 P 2509.

[4]. Berg J . M, Tymoczko J. L, Stryer L. Biochemistry. 5th edition. New York.W.H Freeman Company. 2002.. http: // www WhFreeman.com

[5]. Bedino, J.H. EmbalmingChemistry:Glutaraldehyde versus Formaldehyde: The Champion Company No.609. 2003.

[6]. Tong, G . Characterization of Cysteine-34 in Serum Albumin. Dissertation

[7]. Presented in Partial fulfillment of the requirements for the Degree Doctor of Philosophy in the Graduate School of The Ohio State University., 2003

[8]. Polgar, L. Mercaptide-imidazolium ion-pair: the reactive nucleophile in papain catalysis. FEBS Letters 47, 1974 15-18. 